\title{
ARTICLE
}

Cite this: DOI: $10.1039 / \times 0 \times x 00000 x$

\section{Temperature-controlled reversible exfoliation- stacking of titanate nanosheets in an aqueous solution containing tetraalkylammonium ions}

Received 00th January 2012, Accepted 00th January 2012

DOI: $10.1039 / \times 0 \times x 00000 x$

www.rsc.org/

\begin{abstract}
Kai Kamada ${ }^{a}$ and Nobuaki Soh ${ }^{b}$
Exfoliation and stacking of titanate nanosheets dispersed in aqueous solutions containing tetraalkylammonium ions can be reversibly controlled by adjusting the solution temperature as a tunable physical parameter. That is, the transparent colloidal solution of exfoliated titanates is clouded on the basis of spontaneous staking of multiple nanosheets when heated at a certain temperature, and cooling of the clouded solution causes regeneration of the original exfoliated state. This cycle repeatedly and rapidly occurs according to the temperature fluctuation. The origin of behavior is qualitatively interpreted with a temperature-dependent variation in the Debye screening length of negatively charged nanosheets that affects the dispersibility of nanosheets.
\end{abstract}

\section{Introduction}

Layered metal oxides are applicable for numerous applications because of their unique properties including intercalation, ion exchange, and a peculiar electrical character based on crystal anisotropy. The oxides dispersed in solution can be delaminated to single thin layers (so-called nanosheets) by intercalation of bulky ions or molecules. The exfoliated nanosheets can be restacked through interstratifying of different guests (ions, molecules, or nanoparticles) with an opposite surface charge to the nanosheets. This method has been widely exploited for fabricating a variety of inorganic/inorganic, ${ }^{1,2}$ inorganic/organic, ${ }^{3}$ and inorganic/bio nanohybrids. ${ }^{4-6}$ At present, our trust is that the exfoliation-restacking route is one of important techniques to bring out a synergetic function of host layer and guest species.

A dispersibility of exfoliated nanosheets depends on many factors such as size and charge density of nanosheets and guest species to be intercalated, solution $\mathrm{pH}$, and ionic strength. This fact implies a difficulty in precious, especially reversible control of the exfoliation-stacking phenomenon. Shi et al. have reported that oxide nanosheets intercalated with protein molecules are re-exfoliated by adjusting a solution $\mathrm{pH}$ to cause an electrostatic repulsion between the nanosheets and the proteins. ${ }^{7}$ However, the conventional dispersion control was carried out by titration with acid or base to manipulate solution $\mathrm{pH}$ or addition of dispersant, which inevitably results in an increase of ionic strength, suggesting a poor multiple reversibility between two different solution conditions. In other words, there is no reliable method to accomplish a repeatable exfoliation-stacking behavior.

The present study firstly reveals that the exfoliation-stacking of titanate nanosheets, which are the most often-used oxide layers, can be alternatively induced by controlling a solution temperature that is one of externally tunable physical parameters. More concretely, the delaminated titanate nanosheets in an aqueous solution are spontaneously stacked when heated, and then cooling of solution brings about regeneration of the original delaminated state. This cycle repeatedly occurs according to the temperature fluctuation. Such temperature-dependent reversible exfoliation-stacking behavior may be employed for an efficient recovery and release system of target ions/molecules, improvement of high temperature durability of fragile functional biomolecules by insertion into interlayer space, and temperature-sensitive optical devices utilizing an absorbance change based on the lamination of multiple nanosheets.

\section{Results and discussion}


The stable colloidal suspension of titanate nanosheets was prepared by hydrolysis of titanium(IV) tetraisopropoxide (TTIP) according to the protocol reported by Ohya and coworkers. ${ }^{8}$ Briefly, the liquid TTIP was added to an aqueous solution of tetraalkylammonium hydroxide $\left(\mathrm{R}_{4} \mathrm{~N}^{+} \mathrm{OH}^{-}, \mathrm{R}=\right.$ methyl $\left(\mathrm{TMA}^{+}\right)$, ethyl $\left(\mathrm{TEA}^{+}\right)$, propyl $\left(\mathrm{TPA}^{+}\right)$, or butyl $\left.\left(\mathrm{TBA}^{+}\right)\right)$, followed by heating with gentle shaking at $60{ }^{\circ} \mathrm{C}$ for $2 \mathrm{~h}$. The obtained solutions (named as $\mathrm{R}_{4} \mathrm{~N}^{+}-\mathrm{TiO}_{\mathrm{x}}$ hereafter) were colorless and transparent at room temperature independent of alkyl chain length of $\mathrm{R}_{4} \mathrm{NOH} .{ }^{9,10}$ In the present study, the molar ratio of $\mathrm{R}_{4} \mathrm{~N}^{+}$to titanium was fixed to 1.4 . Raman scattering measurement (Fig. 1S) revealed that the nanosheets had a similar crystal structure to tetratitanate $\left(\mathrm{Ti}_{4} \mathrm{O}_{9}{ }^{2-}\right)$ as suggested in the previous paper. ${ }^{8}$

The particle size of nanosheet was evaluated by dynamic light scattering (DLS) measurement on assumption that the crystal has a spherical morphology even though the nanosheets have a two-dimensional anisotropy in shape. The size distribution curve is composed of single peak (Fig. 1a), suggesting a formation of monodispersed colloidal solution. The mean particle size was estimated to be $4.0 \sim 7.7 \mathrm{~nm}$, and was slightly increased with increasing the alky chain length in $\mathrm{R}_{4} \mathrm{~N}^{+}$(Fig. 1b).
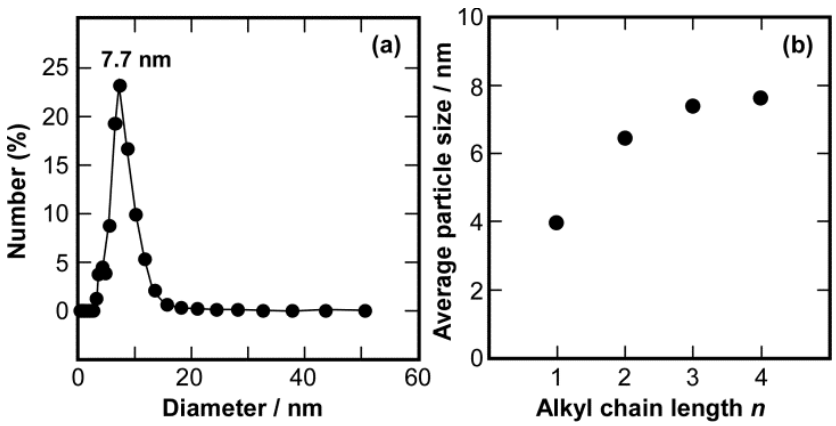

Fig. 1. (a) Particle size distribution curve of $\mathrm{TBA}^{+}-\mathrm{TiO}_{\mathrm{x}}$ colloidal solution at room temperature. (b) Mean particles sizes of titanate nanosheets prepared by hydrolysis of titanium tetraisopropoxide with aqueous solution of various tetraalkylammounium hydroxides $\left(\left(\mathrm{C}_{n} \mathrm{H}_{2 n+1}\right)_{4} \mathrm{NOH}, n=1 \sim 4\right)$.

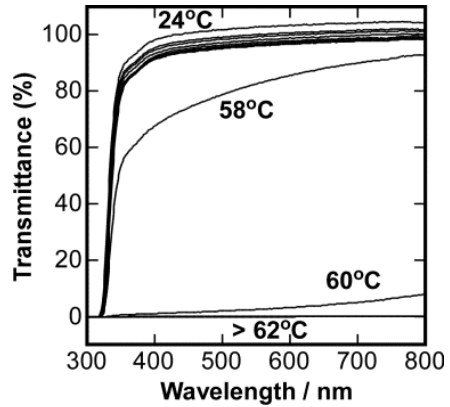

Fig. 2. Transmission spectra of titanate colloidal solution including $\mathrm{TBA}^{+}$ions at various temperatures.

Fig. 2 shows optical transmission spectra of the $\mathrm{TBA}^{+}-\mathrm{TiO}_{\mathrm{x}}$ colloidal solution at different temperatures. At an ambient condition $\left(24^{\circ} \mathrm{C}\right)$, the colloidal solution was transparent over the wide wavelength range and the absorption edge corresponded to the band gap energy of host titanate layer appeared at $365 \mathrm{~nm}$ (3.39 eV), which was agreed with the reported data for $\mathrm{TBA}^{+}$-intercalated tetratitanate powder (3.25 $\mathrm{eV}) .{ }^{11}$ According to the literatures, ${ }^{12-16}$ in the case of titanate nanosheets fabricated via a solid state reaction and a subsequent ion exchange, it has been reported that a colloidal solution contains tiny stacks composed of a few nanosheets (average stack number $<5$ ) besides the single nanosheets (fraction $>0.7$ ) even at room temperature. While heating, the solution started clouding around $58{ }^{\circ} \mathrm{C}$, and the transmittance reached $0 \%$ over the entire wavelength range at $62^{\circ} \mathrm{C}$.

To elucidate the origin of opacificaton, the $\mathrm{TBA}^{+}-\mathrm{TiO}_{\mathrm{x}}$ colloidal solution was dried on a glass plate at various temperatures, and then an X-ray diffraction pattern was measured using a $\mathrm{Cu}-\mathrm{K} \alpha$ radiation. As shown in Fig. 3a, the XRD pattern of sample deposited at $25{ }^{\circ} \mathrm{C}$ displayed a single diffraction line, assigned to the (200) plane of tetratitanate that is parallel to the two-dimensional interlayer space of nanosheets. ${ }^{17,18}$ The interlayer distance $(0.94 \mathrm{~nm})$ calculated by the $d$-spacing $(1.69 \mathrm{~nm})$ and the nanosheet thickness was nearly equal to the ionic size of $\mathrm{TBA}^{+}(\sim 1.0 \mathrm{~nm}) .{ }^{11}$ That is, the $\mathrm{TBA}^{+}$ was interstratified between the negatively charged titanate layers during the drying. Fig. 3b indicates the dependence of drying temperature on the $d$-spacing of (200) plane and a stack number of nanosheets. The stack numbers were calculated by dividing the crystallite size along the [200] direction estimated using the Scherrer equation by the $d$-spacing. The crystallite size at $25^{\circ} \mathrm{C}$ was estimated to be ca. $35 \mathrm{~nm}$, and was larger than that obtained by the DLS measurement as expected. This indicates that the nanosheets were aggregated during the drying procedure. In contrast that the drying temperature had less effect on the $d$-spacing, the stack number dramatically increased at more than $60{ }^{\circ} \mathrm{C}$. Taking into account the sudden reduction of transmittance at $58{ }^{\circ} \mathrm{C}$ (Fig. 2), the opaque state at high temperature should be originated from multiple assembly of more nanosheets.

Fig. 4 plots the transmittance at $550 \mathrm{~nm}$ of colloidal solutions fabricated using four kinds of $\mathrm{R}_{4} \mathrm{~N}^{+}$as a function of the solution temperature. Compared with the $\mathrm{TBA}^{+}-\mathrm{TiO}_{\mathrm{x}}$, the $\mathrm{TPA}^{+}-\mathrm{TiO}_{\mathrm{x}}$ started the clouding, but the clouding started at a higher temperature. In the cases of small $\mathrm{R}_{4} \mathrm{~N}^{+}\left(\mathrm{TEA}^{+}\right.$and $\mathrm{TMA}^{+}$), the full opacification did not occur below $100{ }^{\circ} \mathrm{C}$, where the accurate measurements above $100{ }^{\circ} \mathrm{C}$ was impossible due to boiling. These results revealed that the temperature initiating the opacification was tended to drop with extending the alkyl chain. Consequently, it is summarized that the $\mathrm{R}_{4} \mathrm{~N}^{+}$employed for the hydrolysis of TTIP notably influences the assembling process of nanosheets. 

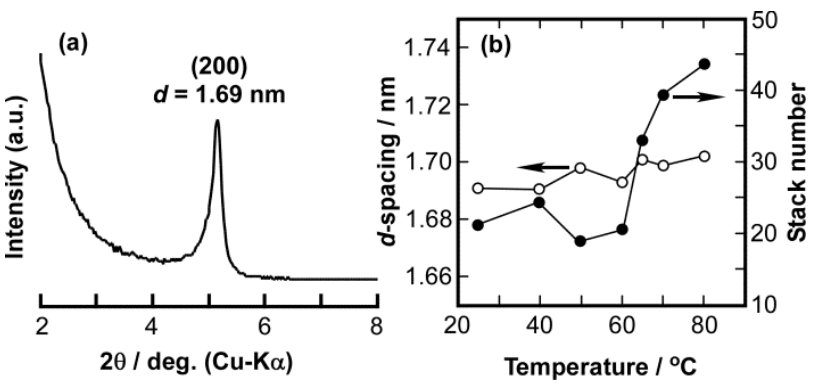

Fig. 3. (a) XRD pattern of $\mathrm{TBA}^{+}-\mathrm{TiO}_{\mathrm{x}}$ after drying of the colloidal solution at $25{ }^{\circ} \mathrm{C}$. (b) Influence of drying temperature on $d$-spacing of (200) plane and stack number of $\mathrm{TBA}^{+}-\mathrm{TiO}_{\mathrm{x}}$.

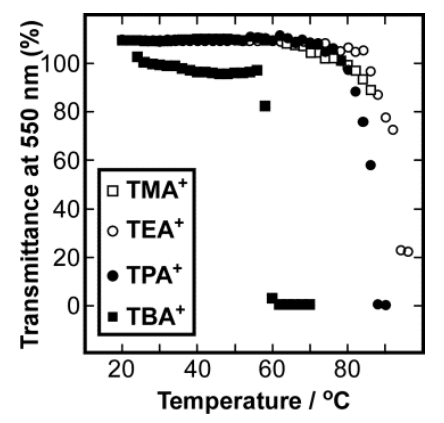

Fig. 4. Changes in transmittance at $550 \mathrm{~nm}$ of titanate colloidal solutions prepared by several kinds of tetraalkylammonium (TMA ${ }^{+}$, $\mathrm{TEA}^{+}, \mathrm{TPA}^{+}$, and $\mathrm{TBA}^{+}$) hydroxides at elevated temperature.
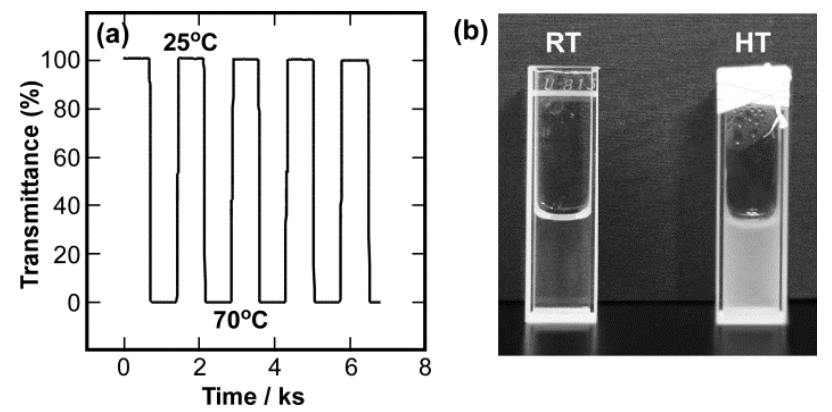

Fig. 5. (a) Transient transmittance at $550 \mathrm{~nm}$ of $\mathrm{TBA}^{+}-\mathrm{TiO}_{\mathrm{x}}$ during temperature switching between 25 and $70{ }^{\circ} \mathrm{C}$. (b) Photographs of $\mathrm{TBA}^{+}-\mathrm{TiO}_{\mathrm{x}}$ colloidal solution at room (RT) and high temperature (HT: around $60^{\circ} \mathrm{C}$ ).

Fig. 5a monitors the transmittance $(550 \mathrm{~nm})$ of $\mathrm{TBA}^{+}-\mathrm{TiO}_{\mathrm{x}}$ during the alternative temperature switching between 25 and 70 ${ }^{\circ} \mathrm{C}$, where the appearances of solution at both temperatures are also displayed in Fig. 5b. As stated already, the solution completely got turbid at $70{ }^{\circ} \mathrm{C}$, but was returned to the transparent (exfoliated) state when cooled to $25{ }^{\circ} \mathrm{C}$. In addition, the phenomenon took place rapidly and repeatedly. In contrast, when the switching was repeated between 25 and $90{ }^{\circ} \mathrm{C}$ many times, the solution gradually became turbid even at $25^{\circ} \mathrm{C}$. This is due to formation and growth of anatase $\left(\mathrm{TiO}_{2}\right)$ crystals with a relatively narrow band gap $(3.2 \mathrm{eV}) .{ }^{19}$ Therefore, it was demonstrated that the exfoliation-stacking of titanate nanosheets was reversibly controlled by the solution temperature below $70{ }^{\circ} \mathrm{C}$.
As reported previously, the Debye screening length $(k)$ is convenient to deduce dispersion stability of nanosheets existing in solution. ${ }^{12}$ According to the Gouy-Chapman model, surface potential $\phi_{0}$ of charged particles in solvent is attenuated due to adsorption of counter ions and those existing in the diffused electric double layer. An effective potential $\phi$ at a distance $x$ from the particle surface can be described as following equations:

$$
\begin{gathered}
\phi=\phi_{0} \mathrm{e}^{-x / k}(1) \\
k=\left(\varepsilon k_{B} T /\left(2 N_{A} e^{2} I\right)\right)^{1 / 2}(2)
\end{gathered}
$$

where, $\varepsilon$ is the dielectric constant of medium, $k_{B}$ is the Boltzmann constant, $T$ is the temperature, $N_{A}$ is the Avogadro constant, $e$ is the elementary charge of an electron, and $I$ is the ionic strength. Judging from a positive relationship between the Debye screening length $k$ and the electric double layer thickness, the dispersion stability of charged particles enhances as $k$ increases. In the present study, for instance, the decline in $k$ would weaken the repulsion between the negatively charged titanate nanosheets, causing their restacking accompanied by sandwiching the $\mathrm{R}_{4} \mathrm{~N}^{+}$.

The temperature controlled reversible exfoliation-stacking of titanate nanosheets shown in Fig. 5a can be interpreted using the Debye screening length $k$. Even though $k$ is extended by increasing $T$ (eq 2), the dielectric constant $\varepsilon$ of water is reduced more rapidly than the temperature rising. ${ }^{20,21}$ As a result, the term $(\varepsilon T)^{1 / 2}$ decreases by heating as shown in Fig. 2S. Thus, the $k$ would be shortened by heating at a constant $I$. In this argument, isopropanol generated by the hydrolysis of TTIP was ignored because the concentration was constant for all colloidal solutions prepared here. Moreover, the rise in the ionic strength $I$ due to enhancement of dissociation constant of water molecule at high temperature might affect the reduction of $k$. Consequently, the titanate nanosheets tend to be assembled at high temperature, and the re-exfoliation occurs by cooling the solution. The effect of solution temperature on the zeta potential of titanate nanosheets is displayed in Fig. 6. As discussed above, it was confirmed that the zeta potential related to the apparent surface charge became smaller at elevated temperature. Hence, it can be concluded that the temperature controlled reversible exfoliation-stacking is induced by the fluctuation of the Debye screening length, i.e., the effective surface potential of negatively charged nanosheets.

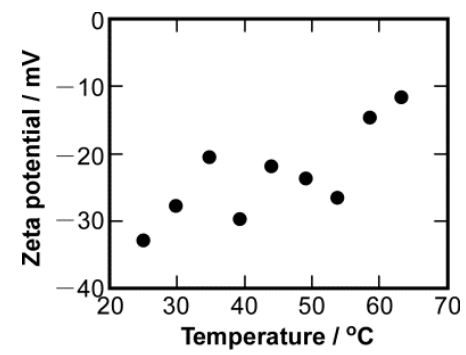

Fig. 6. Temperature dependence on zeta potential of titanate.

\section{Experimental}


Colloidal solution of titanate nanosheets was synthesized via a hydrolysis of titanium tetraisopropoxide (TTIP) as previously reported by Ohya et al. ${ }^{8}$ The TTIP $(0.608 \mathrm{mmol})$ was added to an aqueous solution containing $0.525 \mathrm{M}$ tetraalkylammonium hydroxide $\left(\mathrm{R}_{4} \mathrm{~N}^{+} \mathrm{OH}^{-}, \mathrm{R}=\right.$ methyl $\left(\mathrm{TMA}^{+}\right)$, ethyl $\left(\mathrm{TEA}^{+}\right)$, propyl $\left(\mathrm{TPA}^{+}\right)$, and butyl $\left.\left(\mathrm{TBA}^{+}\right), 1.62 \mathrm{ml}\right)$, meaning that the molar ratio of $\mathrm{R}_{4} \mathrm{~N}^{+}$to $\mathrm{Ti}$ was 1.4 . After the addition of TTIP, the concentration of isopropanol in the mixed solution was calculated to be $c a .1 .35 \mathrm{M}$. The mixture was gently shaken at $60{ }^{\circ} \mathrm{C}$ for $2 \mathrm{~h}$ to obtain the colloidal solution of titanate nanosheets. The crystal structure of nanosheets was evaluated by Raman spectroscopy (JASCO, NRS3000) and X-ray diffraction (XRD, Rigaku RINT2000VL) after drying the colloidal solution on a $\mathrm{Pt}$ and a glass plate, respectively. The particle size of nanosheets in the solution was estimated by dynamic light scattering method (DLS, Malvern HPPS).

Exfoliation-stacking behavior of the titanate colloidal solution was evaluated using a UV-VIS spectrophotometer (JASCO, V650). The colloidal solution $(1.8 \mathrm{ml})$ was injected into a quartz cuvette with a screw cap, and then a transmission spectrum $(\lambda=800 \sim 300 \mathrm{~nm})$ was measured at various temperatures up to $100{ }^{\circ} \mathrm{C}$. Dependence of temperature on zeta potentials of the colloidal solution was estimated using an electrophoretic laser light scattering spectrophotometer (Ohtsuka Electronics, ELS7500N).

\section{Conclusions}

The present study proved that the exfoliation and stacking of titanate nanosheets in the aqueous solution containing the tetraalkylammonium ions could be reversibly and repeatedly caused by adjusting the solution temperature. The origin of behavior was qualitatively discussed on the basis of temperature dependence on several factors governing the Debye screening length of negatively charged titanate nanosheets. As a result, the changes in the dielectric constant of water and the ionic strength were considered to reflect the temperature-dependent variation of the Debye screening length affecting the colloidal stability. In the future, the phenomenon will be investigated for various other oxide nanosheets.

\section{Acknowledgements}

The present work was partly supported by Grant-in-Aid for Young Scientists (No. 24750205 and 24750072) from Japan Society for the Promotion of Science (JSPS).

\section{Notes and references}

${ }^{a}$ Department of Materials Science and Engineering, Faculty of Engineering, Nagasaki University, Nagasaki 852-8521, Japan.

${ }^{b}$ Faculty of Agriculture, Saga University, Saga 840-8502, Japan.

Electronic Supplementary Information (ESI) available: Raman spectrum of $\mathrm{TBA}^{+}-\mathrm{TiO}_{\mathrm{x}}$ and temperature dependence of $\left(\varepsilon_{r} T\right)^{1 / 2}$ of water. See DOI: $10.1039 / \mathrm{b} 000000 \mathrm{x} /$

1 J.-H. Choy, H.-C. Lee, H. Jung and S.-J. Hwang, J. Mater. Chem., 2001, 11, 2232.
2 S.-M. Paek, J.-H. Kang, H. Jung, S.-J. Hwang and J.-H. Choy, Chem. Commun., 2009, 7536.

3. U. Unal, Y. Matsumoto, N. Tanaka, Y. Kimura and N. Tamoto, J. Phys. Chem. B, 2003, 107, 12680.

4. C. V. Kumar and A. Chaudhari, Chem. Commun., 2002, 2382.

5. C. V. Kumar and C. V.; Chaudhari, J. Am. Chem. Soc., 2000, 122, 830.

6. K. Kamada, T. Nakamura and S. Tsukahara, Chem. Mater., 2011, 23, 2968.

7. Q. Wang, Q. Gao and J. Shi, Langmuir, 2004, 20, 10231.

8. T. Ohya, A. Nakayama, T. Ban, Y. Ohya and Y. Takahashi, Chem. Mater., 2002, 14, 3082.

9. T. Ban, S. Yoshikawa and Y. Ohya, CrystEngComm, 2012, 14, 7709.

10. K. Kai, Y. Yoshida, H. Kageyama, G. Saito, T. Ishigaki, Y. Furukawa and J. Kawamata, J. Am. Chem. Soc., 2008, 130, 15938.

11. M. R. Allen, A. Thibert, E. M. Sabio, N. D. Browning, D. S. Larsen, and F. E. Osterloh, Chem. Mater., 2010, 22, 1220.

12. R. Besselink, T. M. Stawski, H. L. Castricum, D. H. A. Blank and J. E. ten Elshof, J. Phys. Chem. C, 2010, 114, 21281.

13. T. Tanaka, Y. Ebina, K. Takada, K. Kurashima and T. Sasaki, Chem. Mater., 2003, 15, 3564.

14. M. Harada, T. Sasaki, Y. Ebina and M. Watanabe, J. Photochem. Photobiol. A, 2002, 148, 273.

15. M. Gteshki, S.-J. Hwang, D. H. Park, Y. Ren and V. Petkov, Chem. Mater., 2004, 16, 5153.

16. M. Watanabe and T. Sasaki, J. Am. Chem. Soc., 1998, 120, 4682.

17. W. Sugimoto, O. Terabayashi, Y. Murakami and Y. Takasu, J. Mater. Chem., 2002, 12, 3814.

18. S. Uchida, Y. Yamamoto, Y. Fujishiro, A. Watanabe, O. Ito and T. Sato, J. Chem. Soc., Faraday Trans., 1997, 93, 3229.

19. T. Ban, Y. Tanaka and Y. Ohya, Thin Solid Films 2011, 519, 3468.

20. D. P. Fernández, A. R. H. Goodwin and J. M. H. Levelt Sengers, Int. J. Thermophys., 1997, 16, 929.

21. B. B. Owen, R. C. Miller, C. E. Milner, H. L. Cogan, J. Phys. Chem., 1961, 65, 2065.

TOC
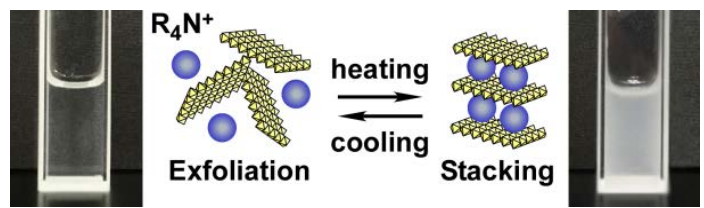

Exfoliation and stacking of titanate nanosheets dispersed in aqueous solutions containing tetraalkylammonium ions can be reversibly controlled by adjusting the solution temperature as a tunable physical parameter. 